\title{
Understanding Formality and Informality in Information System Pre-evaluation (ISIE) Process: Examining Case Research from an Actor Network Theory ANT Perspective
}

Fayiz Dahash Shrafat

Department of Management, Faculty of Economics and Management Science, The Hashemite University, P.O. Box 150459, Zarqa 13115, Jordan

E-mail: f.shrafat@hu.edu.jo

Abdel Hakim O. Akhorshaideh

Department of Public Administration, School of Business Administration

The University of Jordan, Amman 11942 Jordan

E-mail: A.hakim@ju.edu.jo

Ayman Bahjat Abdallah

Department of Business Management, School of Business Administration

The University of Jordan, Amman 11942 Jordan

E-mail: a.abdallah@ju.edu.jo

Zu'bi M. F. Al-Zu'bi (Corresponding author)

Department of Business Management, School of Business Administration

The University of Jordan, Amman 11942 Jordan

E-mail: z.alzubi@ju.edu.jo

Received: Oct. 12, 2015 Accepted: Dec. 1, $2015 \quad$ Published: January 1, 2016

doi:10.5296/jmr.v8i1.8497 URL: http://dx.doi.org/10.5296/jmr.v8i1.8497 


\section{Abstract}

The degree of rigidity in the process of IS evaluation and the dependence on a specific method tends to vary among banks, depending on a combination of many factors. This research focuses on I.S. pre-evaluation as socio-technical process. Central to this is the notion of Request for proposals RFP (Business case) and the analytical toolkit of Actor Network Theory (Latour 1987). Specifically this study attempts to highlight on the level of formality/informality played in the evaluation process by the threads of 'rigidity issues' that manifested themselves on the journey throughout the ex ante I.S. business cases in the bank. The study contributes to the existing literature in IS evaluation research by drawing using this case study to infer how pre-evaluation practices are being affected by the developing country context of Jordan. Among the several findings drawn from this research, the informal use of intuition was accommodated within the formal process of IS evaluation demonstrated to be the most prominent. The study highlights the importance of informal evaluation that of "gut feeling" and experience of executives which plays a significant role in the IS evaluation process.

Keywords: information system, IS evaluation (ISIE), informal/formal IS pre-evaluation, request for proposal, actor network theory, interpretive and qualitative research. 


\section{Introduction}

Information technology/information systems (IT/IS) has been extensively used so that it is hard to conceive of any organisation in an industrialised nation, and even in a developing nation, not using some form of IT/IS. The fast growth of IT/IS investments has put challenges on managers to consider investment risks and returns in decision-making (Kim \& Sanders, 2002). Choosing and successfully implementing the right IT/IS investments can be a focal point in sustaining organization's viability and growth (Bacon, 1992). Since we are intending to measure both of tangible and intangible benefits, IS evaluation is becoming much more complicated than it was before (Coombs, 2015). Seddon et al. (2002) concluded that, IS evaluation is hardly moving from the financial perspective to a business-oriented one.

The use of formal evaluation methods may cause incorrect IT investment decisions without considering the intangible benefits (Anandarajan \& Wen, 1999; Lubbe \& Remenyi, 1999; Irani, 2002; Law \& Ngai, 2005; Moretto et al., 2014). Irani et al. (2002) describe that organizations would prefer to achieve long-term strategic benefits, however, this can't be realised by applying traditional evaluation techniques and would deemed to be inappropriate. Irani et al. (2006) explained that if the reduction of operational cost was a top priority of an IT project, then traditional evaluation techniques are adequate. However, a newer perspective like balanced scorecard might be the right alternative for formal assessment purposes when a project attempts to use IT for strategic goals. One of the major challenges for business managers as regards of strategic IT investment assessment is to identify qualitative, intangible, or unobserved value. Also, a strategic IT implementation entails complementary corporate assets and business modifications in redesigning processes, which may result in inability of separating IT benefits from the total benefits (Brynjolfsson \& Hitt, 2000). To a great extent the types of evaluation approach will depends on the attitude of the manager and what kind of information will be used. The fundamental measures are mostly used by the practitioners (managers) when evaluating IT investments(Ward \& Daniel, 2006).

Leem and Kim (2004) pointed out that there are several limitations experienced in previous IS evaluation studies. First, IS evaluation should be performed throughout the IS development life cycle. However, previous studies evaluated a single stage in IS project. Second, although previous studies have exerted inclusive effort on performance measures and IS-performance relationship, however, the best evaluation approach was not seem to be easily allocated and identified. Third, previous research in general did not investigate business implications of IS evaluation. Hakkinen and Hilmola (2008) mentioned that a variety of approaches and multiple dimensions have further complicated IS evaluation, a reason why a standard evaluation framework is not obtainable. Gunasekaran et al. (2006) note various issues associated with measures, i.e. no agreed upon definition of performance measures and dimensions; no clear distinction among organizational, competitive and operational performance dimensions; and the lack of clarity in determining non-financial and intangible performance measures. To perform an accurate assessment of performance, it is necessary to apply a multiple perspectives of performance measurement and evaluation. McAulay et al. (2002) argued that such a multiple perspectives criterion is expected to yield different results and conclusions. 
Different points of view among different stakeholders exist about benefits and risks, and at the same time, they share differences and similarities. for Willcocks (1992), the worth of IT to an organisation can be examined by deploying quantitative or qualitative evaluation methods. Love et al (2005) assert that evaluation is a process to be understood and that such an understanding should include an awareness of why it is undertaken, the characteristics of the process which is undertaken and its intrinsic complexity (i.e. limitations and problems). Ballantine and Stray (1998) discuss the problem of distinguishing evaluation from appraisal. Gunasekaran et al. (2006) particularly argue that there are no recognized models available to examine effect of IT on organizational performance or to assist in selecting evaluation tools and techniques. There is also a lack of IS evaluation models that are validated.

while many researchers agree that there is a need for IS investment evaluation methods that are more sophisticated and more formal (Irani \& Love, 2002), the debate continues for want of proof of a direct valuable relationship between level of formality and quality in IS evaluation. Keyes-Pearce (2005) argues that it is not necessarily the case that evaluation problems will be resolved by developing new methods. Positive investment evaluation outcomes do not depend entirely on developing new methods, but are affected by the organisational context in which the evaluation is carried out (see section 2.8). There is no clear-cut evidence that more formality will produce more effective IS evaluation processes and vice versa. Moreover, there is very little agreement as to the exact practices deemed to be essential to produce effective evaluation or the ideal level of formality in evaluation practices. Ballantine et al. (1996) state that "the role of formal procedures in the IS/IT evaluation process needs to be more closely examined to identify whether their use results in any significant benefits". To address this gap, this study takes a comprehensive and systemic approach of IT investment evaluation, since its objective is to determine effective practices and grasp why they work.

The motivation for this research is to attempt to investigate the range and aspects of formality/informality that are related to the Information Systems Investment Evaluation (ISIE) process in the banking context, based upon case study research and extant literature. The setting for the case study research is a regional financial services firm. In order to capture the richness and depth required, the researchers take an interpretive approach in analysing the extent of formality/informality in IS evaluation. This current paper investigates how formality/informality in IS evaluation process might be enacted, using the lens of actor-network theory (ANT). The paper is organized as follows. The next section reviews persistent issues with Formality and informality in Information Systems Investment Evaluation (ISIE) as reported in the literature. The third section describes the methodology and discusses the analytical toolkit of Actor Network Theory. The data analysis and findings are presented in the fourth section. The finding are discussed in the fifth section in the light of the IS evaluation literature. The concluding section summarizes the main findings and study limitations, and discusses implications for future research.

\section{Theoretical Background}

The theoretical foundations for this research are based on two main aspects of research, namely formality and informality in Information system pre- evaluation (ISIE). A review of relevant literature on these perspectives is reviewed below. 


\subsection{Formality in Information Systems Investment Evaluation (ISIE)}

Formality in IS evaluation can be defined as having an established structure and procedure to carry out an IS evaluation process with a scheduled set of meetings at different hierarchical levels and that can be followed to provide transparency and rigour when rational decisions is to be taken regarding IT investment. Thus, Formality has gained lately much attention in IS evaluation. The use of formal techniques is supported by most of the existing research in this field, which shows that better designed methods and more formal techniques are in general linked to more successful evaluations, i.e. enhanced decision making (Remenyi \& Sherwood-Smith, 1999), better consistency (Ward, 1990), greater accuracy (Love \& Irani, 2004) and organizational learning (Land et al., 1992). Ezingeard, Irani et al. (1998) and Lin and Pervan (2000) contend that more structured and formal evaluations are more evident in larger organizations than in smaller ones and that half of organizations endorse formal procedures. Pennington and Wheeler (1998) recommend avoiding qualitative criteria that might reduce the level of rationality in decision making, while others agree that this could be problematic (Ward, 1990, Hallikainen et al., 1998; Hallikainen \& Chen, 2012). Powell (1999) argues that major IS investment without formal evaluation is indeed a problematic issue. Further, Sohal and $\mathrm{Ng}$ (2001) contend that the potential of IS has not been met due to an inadequate and unsuitable evaluation of suggested IT investments. According to Semich (1994), to evaluate IS objectively, formal criteria should be implemented.

When the use of IS by an organisation has a strategic intention, then the design of the evaluation becomes extremely significant. Tallon (2008) concur that in such cases, "there is an even greater need for these investments to undergo routine, systematic and recurring evaluation". Hence, IS evaluation is considered one of the most significant unresolved issues in information management (Nijland, 2004). Irani and Love (2008) cite Paul (2007), who describes this notion of an IS as comprising two components:

First, the formal processes are supposed to be pre-defined regarding which IT should be used. However, the processes have afterwards to be rapidly modified in two ways: first each time the system varies from the expected performance, and second whenever there is a need to adapt the system to respond to dynamic surrounding environment.

Second the informal processes, which are what the employees who use the IT and the formal processes create or invent so that to verify that appropriate work is done.

A combination of formal and informal evaluation processes adapted by the users of the IS has been recommended as practicable. The IS may be modified at any time, requiring the formal processes to be redefined, so in practice the users will need to design an informal process which will function appropriately. At this point it can be assumed that there is a meaning associated with IS, that is, the result emerging from the adaptive practices of the IS and the associated evaluation process (Paul, 2007). In several organizations, formal evaluation methods are not available, and where they are available, they are not always used or imposed; instead, a project champion is left to decide the method(es) believed to be suitable and adequate to achieve project approval and financial support (Farbey et al., 1992; Thomaidis et al., 2006; Sims et al., 2015). It is challenging for managers when they have to choose the 
most appropriate evaluation approach to use, but it is essential that stakeholders' opinions are considered and that decisions are not made entirely from a traditional financial perspective. Ballantine et al. (1999) found that half of the organizations that they investigated had no formal evaluation procedures.

Gunasekaran et al. (2001) argue that there are few commonly acknowledged strategies for IS investment evaluation, with much research finding that many organisations have no formal IS evolution process and lack adequate auditing techniques by which project goals can be evaluated (Primrose \& Leonard, 1987; Kumar, 1990; Kennedy \& Mills, 1992; Lin \& Pervan, 2003; Sims et al., 2015). This argument is confirmed by Hochstrasser (1992), whose survey found that 16 per cent of organizations sampled were applying accurate techniques to assess their IT investments. Other researchers, such as Currie (1995), report slightly better results. Ward (1990) argues that the most suitable IS investments were not selected as a result of the lack of formal evaluation. Many authors agree that formal evaluation is essential in determining the actual impact of an IS on business performance (Irani \& Love, 2002), in enhancing future decision making, in improving system use (Wilson \& Howcroft, 2005), in justifying IS investment (Al-Shehab et al., 2005) and in contributing to organisational learning (Willcocks \& Lester, 1999b).

Connolly (2008) asserts that challenging too many IS investment projects simultaneously or the incorrect portfolio of projects can also have terrible outcomes (Ross \& Weill, 2002). Moreover, the impact of IS adoption on an organization can be catastrophic when a project is poorly developed, but when an IS project is implemented properly, service intensity and overall firm performance will be improved considerably (Weber \& Pliskin, 1996; Maizlish \& Handle, 2005; Bowen et al., 2007; Ashrafi \& Mueller, 2014). Therefore it is crucial when considering any significant IT investment to follow a rigorous, formal and disciplined process to ensure the right mix of projects. These, in turn, will ensure desirable results and the creation of real value for the organization (Chan \& Reich, 2007; Holland \& Skarke, 2008). According to Mitev and March (1998), positive outcomes are facilitated by formality and rigour in IS evaluation, which provides "a scheduled set of occasions for face-to-face communication across multiple levels of hierarchy, thus giving the chance to debate the specific project". Marsh and Flanagan (2000) add that formal evaluation enables the organisation to offer "a clear paper trail, showing the documents submitted at each stage, the minutes of committees and meetings and a record of the point at which capital was officially committed".

Notwithstanding these recommendations, many IS assessment decisions rely on gut feeling and instinct (Marshall \& McKay, 2002; Bannister et al., 2004) and rationality is often lacking in decision making (Symons \& Walsham, 1991; Avison et al., 1995; Ballantine et al., 2000; Ali \& Younes, 2012). Indeed, organisational research confirms that little consideration is paid to formal IS investment evaluation in practice; considerable and substantial IS investments decisions have been identified as "acts of faith", "got to do" or simply "strategic"; and where formal evaluation does take place it tends to use an accounting based method, incurred early in the project lifecycle (Kumar, 1990; Willcocks, 1992; Love \& Irani, 2004; Goldkuhl \& Lagsten, 2012). Yet there is an obvious need for formal IS evaluation (Irani \& Love, 2001). 
Financial disaster is evident if formal evaluation of any investment has been disregarded (Clemons, 1991). Therefore the view that adequate quantitative evaluation of strategic systems is made impossible by the lack of data has been challenged. Betz (2006) calls for a more sophisticated approach to IS evaluation and control, with particular focus on the development of successful and capable IT evaluation processes, reliable measures and logical decision making. He emphasises the necessity for improved general governance and control systems, particularly with regard to employees, preferences and performance. Alshawi et al. (2003) and Love et al. (2004) emphasise that if organizations seek to develop their business performance they must carry out a more systematic and rigorous evaluation processes prior to IS implementation. Regardless of such evidential support and influential academic calls for a systematic and more accurate evaluation of IS investment, it seems that many organizations do not gather enough information regarding IS performance, so evaluation techniques still unreliable (Willcocks \& Lester, 1997).

\subsection{Informality in Information Systems Investment Evaluation (ISIE)}

As noted above, not much consideration has been paid in practice to formal IS investment evaluation. Several significant investments have been reconceptualised on the basis of intuition and acts of faith. According to Bannister and Remenyi (2000), the term 'act of faith' appears in a variety of forms throughout the literature (Farbey et al., 1993; Dietz \& Renkema, 1995; Farbey et al., 1999; Bannister \& Remenyi, 2000), as do 'blind faith' (Weill, 1990), 'gut instinct' (Powell, 1992; Katz, 1993) and 'strategic insight', which means the same thing. Most of the formal evaluation which occurs prior to any IS investment decision happens very early in the project lifecycle (Kumar, 1990; Willcocks, 1992). Ad hoc procedures are applied in the majority of IS justifications. Thus, a customisation of formal methods will be applied to suit the requirement of each specific situation (Farbey et al., 1999). It is clear that decisions on unstructured and complex problems are based on sense or instinct (Bannister \& Remenyi, 1999). Lubbe and Remenyi (1999) concur, reporting that in practice informal methods are used. Many studies of IS investment evaluation and decision making practices have found that managers frequently relied on procedures which cannot be regarded as rational decision making when it comes to very complex situations. It seems that managers base such decisions on intuition and gut feeling (Bannister \& Remenyi, 2000; Irani et al., 2006; Schryen, 2013).

Intuition has been described in the IS literature as extremely innovative; where an IS investment project cannot be justified rationally, evidence shows that evaluation is based on gut feeling (Weill, 1990; Dos Santos, 1991; Powell, 1992; Farbey et al., 1993; Katz, 1993; Barua et al., 1995; Small \& Chen, 1995; Bannister \& Remenyi, 2000). Instinct is essential in IS evaluation because of the influence of both non-financial and non-tangible factors which are not covered by traditional evaluation techniques (Bannister \& Remenyi, 2000). While most deliberate decisions taken by organisations seem to be rational (Straw, 1990), relevant IS investment decisions are not often logical (Bannister \& Remenyi, 1999) or reasonable (Standing, 1998, Bannister \& Remenyi, 1999; Chung \& McLarney, 1999). The result of an evaluation may vary from one evaluator to another or from one period of time to another as a result of using informal evaluation methods (acts of faith, subjective judgments and intuition). A study by Marshall and McKay (2002) found that IS investment evaluation was 
disorganised and dependent on instinct and gut feeling. Yet the originally intended benefits and business value can only be achieved if the organisation uses appropriate IS investment evaluation procedures.

Bannister and Remenyi (2000) propose a three-level taxonomy, classifying approaches to IS investment evaluation as fundamental, composite and meta-methods, which can be implemented in positivist, reductionist or hermeneutic ways. The first specified approach is the positivist/reductionist one, where the methodology is allowed by the decision maker to make the decision and the investment with maximum return is selected. The second is the hermeneutic approach, defined as approaches of elucidation of data which use non-systematic procedures to both sensing and decision making. According to this approach, decision makers adopt several metrics and integrate them in mind in such a way that it will be difficult to state them formally.

The authors conclude that in the hermeneutics approach, "instinct and intuition play the biggest role". Instinct, according to Bannister and Remenyi (2000) is thus not essentially something to be condemned or abandoned by the rational decision maker. The authors describe instinct, intuition and gut feeling as as a super rational approach which leads to integrating the processes of reasoning at an advanced level compared with step by step problem solving approach.

There is a restriction on what can be achieved by applying formal rational evaluation methods when tracing the effect of evaluation methodologies on what is called the 'investment opportunity space'. This restriction is far from obvious when decision makers substitute formal procedures with gut feeling and other subjective/intuitive methods. In a study of intuitive decision making by professionals, Burke and Miller (1999) found that $56 \%$ of participants based their decisions on experience, while $40 \%$ based them on feelings when given information. The authors state that this raises questions as to what kind of information informed these instinctual decisions and how it influenced the results. Two thirds of their respondents felt that better decisions had been driven by intuition (Burke \& Miller, 1999), but according to Martins and Kambil (1999), this is not the case: their study shows that managers had less appreciation of past experience in decision making. Bonabeau (2003) argues that as the complexity of a situation increases, the confusing intuition increases, so that intuition should be given less weight when a situation involves evaluating multiple alternatives, a large amount of data and more "unprecedented challenges". The author stresses that intuition can be replaced by reason, although it should not be ignored entirely in decision making. As explained in the previous paragraph, Bannister and Remenyi (2000) support the view that the rational decision maker should not abandon or condemn instinct. Nevertheless, transparency and acknowledgement of uncertainty are missed when decisions are based on intuition, which may thus produce the unrealistic logic of being secure while making decisions which will lead the eventual failure of the IS project. Disastrous decisions will continue to be made unless the real reasons behind complex decisions are acknowledged (Jamieson et al., 2007). Hirschheim and Smithson (1999) warn that when investing in strategic IS managers sometimes prefer to take a chance, rather than relying on rational decision making. The 
suggestion appears to be that informality is dangerous, but the literature offers no obvious results proving whether informality leads to successful IS evaluations or not.

While Bannister and Remenyi (2000) and Bonabeau (2003) indicate that instinct has a significant and important role in IS evaluation, Marshall and McKay (2002) conclude that the intuitive approach to evaluation in itself does not seem to be predominantly effective. Many authors have confirmed the significance that evaluation plays in making decisions regarding IS investment projects; however, other studies have indicated that formal evaluation is actually often seen as unhelpful because of the need to overcome difficulties in the financial justification process (Irani \& Anandan, 1998; Farbey et al., 1999b). As a result of this, an informal evaluation process often takes place, permitting champions of IS projects who are completely dedicated to accomplishing the project to search for unseen potential benefits and to reduce potential project costs (Nutt, 1997, Irani \& Ghoneim, 2002; Irani \& Love, 2002). Lovallo and Kahneman (2003) justify this by stating that decision makers make their decisions relying on delusional optimism instead of rational weighted average approach which includes payoffs and losses with their prospective probabilities. Bannister and Remenyi (2003) point out that evaluation is such an important component in justifying IS investment that it consists of a range of operations and elements: "some rational, some non-rational, some explicit, others implicit". The above discussion indicates that in order to reach a full understanding of IS evaluation it is essential to perform more studies that shed light on the potential balance between formality and informality, which is something that the study reported in this study attempts to do.

\section{Research Methodology}

This study uses an interpretive approach to look into the complexity and the dynamic character of the interrelated elements of the IT/IS investment pre-evaluation process in the Jordanian banking system. Interpretivists search for meaning in social context and would argue that the methods used by the natural sciences are both unsuitable and insufficient for investigating social phenomena (Barrett \& Walsham, 2004; Oates, 2005; Black, 2006). Here, IT/IS pre-evaluation is considered to be a socially constructed reality and the interpretivist paradigm seeks a better understanding of the associated meanings to facilitate interpretation and to explain the observed phenomena (Lopez \& Willis, 2004).

Information systems, as Klein and Myers (1999) clearly demonstrate, get knowledge from social interactions such as awareness, language, symbols, documents, interviews, stories, shared meanings and other interactions. The context that influences the process and the outcome is the main interest of the interpretive researcher (Harvey \& Myers, 1995; Klein \& Myers, 1999). IT/IS evaluation involves a high level of complex interrelation among disparate entities: IT, people and organisational factors. Since IS represents a social process that is dynamic, it cannot be put into a model to be understood using a positivist approach, which has always been engaged in developing fixed and predictive relationships and elements, regardless of the context (Myers, 1994a). As the present study deals with the socio-technical complexity of IT/IS investment pre-evaluation, this positivist approach was deemed inappropriate. One of the key strengths of interpretive research is that people are studied in a 
natural setting, rather than artificial or experimental ones, which implies the use of interviews (formal and informal) and observing participants' behaviour.

Most of the data was collected from a Jordanian bank, which will be referred to anonymously as CRBA, indicating its status as a commercial and retail bank. Some of the data was drawn from documents which were supplied by participants at the bank. These were collected while the researchers were engaged in conducting interviews; this continuing access to documentation supplied the ways to triangulate interview data with observed behaviour and evaluation process. Interviewees were employees from a cross-section of bank departments, in what follows, participants are referred to as CRBP1, CRBP2, etc., to distinguish them anonymously. As addressing the research problem required in-depth information, data was gathered by means of semi-structured interviews, which are seen as one of the most significant sources of evidence in creating a case study database. This section has justified the decision to adopt an interpretivist research approach. The use of Actor-network theory as an analysis technique is addressed next.

\subsection{Actor-Network Theory: a Theoretical Lens}

In this research, interpretive philosophy have been chosen to guide the researchers in understanding IS pre evaluation practices that are characterized by contextual diversity that influence the perceptions of their stockholders. However, In the Interpretive tradition, there are no right or wrong theories but there are interesting and less interesting ways to observe the world (Walsham, 1993). Therefore, in IS interpretive research as Walsham (2006) noted, the choice of a particular theory is subjective and rely on whether that this theory are interesting to their interpreters or not. As a result, the researchers found ANT interesting and chose it in this study to trace the practices of IS pre -evaluation thought out the investment process. this section discusses ANT's research approach and its selection as the theory for this study.

\subsection{Application of ANT to the Present Study}

The present study had no preconceived theoretical foundation, the research being undertaken to find answers, which had been initially formulated to explain formality/informality in IS pre evaluation process. Therefore, the actors had to be followed in a particular socially constructed environment. IT formed a predefined situation in which the research had to focus on the human actors, their actions and how they interacted with technology, considering all the risks associated with the investment of IT/IS. Moreover, consideration had to be given to IS pre-evaluation practices which influenced the making of decisions and how the actors concerned would measure and evaluate the proposed IT/IS investment projects. In adopting ANT in this study, the researchers assumed that it would be possible to clarify the fine balance between the social and technical aspects of IT/IS evaluation in the Jordanian banking system, by identifying each of the actors, as well as clarifying the actions of those involved in the network.

Since one of the criticisms of ANT is that it does not possess a steady body of knowledge, researchers are advised to focus on the stable parts of the theory, set out in Table 3-2. These 


\section{Macrothink MInstitute"'t}

stable elements of ANT, as listed by Walsham (1997), concentrate on the formation of the aligned network in which they have a mutual interest and the processes that translate these interests into stable networks. As a research methodology, there are no established recommendations for the use of ANT. Walsham (1997) provides the best illustration and justification of the rationale behind the use of ANT as a methodology: it is a combination of both a methodology and a theory... as it does not give a theoretical connotation as a path of observing components in the real world, it also proposes that these components need to be traced in empirical study.

Table 3-2. Stable elements of ANT

\begin{tabular}{ll} 
Concept & $\begin{array}{l}\text { Description } \\
\text { Actor (or actant) }\end{array}$ \\
\hline Beth people and nonhuman actors such as \\
technological artefacts \\
\hline Actor network & $\begin{array}{l}\text { Diverse network of aligned interests, including } \\
\text { persons, companies and standards }\end{array}$ \\
\hline Enrolment and translation & $\begin{array}{l}\text { Establishing allies, human and nonhuman, via a } \\
\text { procedure of converting their interests to be aligned } \\
\text { with the actor network }\end{array}$ \\
\hline Delegates and inscription & $\begin{array}{l}\text { Delegates are actors who "stand in and speak for" } \\
\text { certain opinions which have been engraved in them }\end{array}$ \\
\hline Irreversibility & $\begin{array}{l}\text { The level to which it is thereafter unfeasible to } \\
\text { return to a point where alternative possibilities exist }\end{array}$ \\
\hline Black box & $\begin{array}{l}\text { A frozen network aspect, often with features of } \\
\text { irreversibility, e.g. legal requirements }\end{array}$ \\
\hline $\begin{array}{l}\text { Network aspect with strong properties of } \\
\text { and time, e.g. software standards. }\end{array}$
\end{tabular}

Source: Walsham (1997)

A number of important concepts concerning the transition of ANT from a theory to a method must be mentioned here. Latour (2000) defines centres of calculation as sites "where inscriptions are combined and make possible a type of calculation". In ANT terms, this means that the present case study was carried out in a number of sites called 'centres of calculation', so the IT/IS evaluation process and the bank being investigated are the centres 
of calculation in this study. These represent the bank, events, IT, procedures, strategies, etc. The elimination of any hierarchical ranking among the actors must be ensured in order for a centre of calculation to function as an ANT site, which means that both human and nonhuman actors in the sites should be treated as having equal status and power and should be renamed 'actants'.

Transforming ideas into objects happens as a result of brining all the socio-technical actions of the entities together to form networks. All of the actants must enter into relationships called networks in order to betoken the nature of a site. Each actant in a network has two main roles, which Latour (2000) calls intermediary and mediator, and which make it possible for all actants in the sites to build up networks. In order to differentiate between the two and separate their roles, each has a different character: intermediaries are not permanent but dispensable and very flexible and may be open to manipulation, while mediators are strong entities which tend to remain and add to the networks. Callon (1991) defines an intermediary as "anything passing between actors which defines the relationship between them" and refers to four types of intermediary:

$[\mathrm{T}]$ exts ... or more commonly literary inscriptions ... These contain books, patents, articles, reports, and notes. ... [T] echnical artefacts. These include equipments, technical instruments, robots and consumer goods ... [H] uman beings, and the skills, the knowledge, and the know-how that they integrate. ... [M]oney in all its dissimilar forms.

He describes mediators as talented members with the ability to translate what they convey, to redeploy it, redefine it, and also betray it (Latour, 1992). Intermediaries pass on network elements and make connections between them, while mediators translate these connections into a design which transforms the network into an object. Conceiving of actants in this way makes it easy to separate their roles in the centre of calculation and provides an analytical tool. This entails that there is much work being done behind the scenes. The ways in which actors displace, modify and translate their diverse and conflicting interests are called 'chains of translation'. In this process, chains of translation offer an identification of the problem (problematising) in order to bring everyone interested into the network (interessment), followed by the shaping of teams and their mobilization (enrolment). Tatnall and Gliding (1999) state that that

The theory of innovation translation provides a procedure to describing innovation that does not depend on any supposedly inherent character of the innovation, or specific features of the change agents or society, but instead on a process of network structure in which all actors explore to convince others to become their supporters in promoting the approval of their own view of the best way to solve a problem.

All these activities must be translated into terms that are understood and supported by others, which will make the network stronger. The final product will be a black box, when the result of the translation process applicable to the centre of calculation is no longer susceptible to advanced mediation and the actants within the black box acknowledge this. 
What allowed us to analyze our data without making any distinction between subject and object was the clarity facilitated by using ANT, which informed the method through which we have been able to encompass all actants and realize that both human and nonhuman entities can be actants. Eventually we came to understand how to open up the process and how one actant recruited by another can be helpful in building alliances and strengthening the network. Latour (1992) makes it clear that an actant should be followed in the network so that the researchers can identify what they do or have done, what their plans are, what they think and how they communicate.

\section{Data Analysis and Findings}

\subsection{IS Pre-Evaluation Process [Request for Proposals (Business Case)]}

This stage (business case) was regarded as crucial in having the IS proposal chosen against competing proposals. The business case stage required more restructuring of the IS proposal by engaging and enrolling more actors from other departments. When the request was initiated, the proposal would be presented to the executive committee after being approved by the concerned departments. Furthermore, the end of the development of the IS proposal stage was considered an Obligatory passage point (OPP). The establishment of a business case at CRBA was highly reliant on the role of the head of the relevant business unit (the business case champion). There were difficulties associated with these procedures which in themselves created obstacles to IS investment at the bank.

To understand this point it is important to examine the bank's history and the debate that took place when this vision was in its early stages. However, it proved to be hard to differentiate the influence of business people, as it depended on efficient interaction with other business units of the bank. IS projects were measured against a set of criteria and it is important to consider this, because these indicators were used by business people to help evaluate the outcome of investing in IS, in order to provide support for investment ideas. The bank could then provide a higher level of endorsement and develop a positive attitude, which would help in gaining the approval of the stakeholders. CRBP16 made the following observation on this matter:

The executive committee is not willing to approve any business case unless it has been proven and supported by a solid case that is able to prove itself in an innovative manner.

The development of an IS business case can be seen to have enabled the building of smaller networks that were able to emerge within larger networks and to enrol more actors at different levels and in various areas. The bank and the executive committee responsible for granting approval for IS investment proposals had effectively designed homogeneous networks composed of human and nonhuman actors characterised by their involvement and interest in IS evaluation. Thus, further development of IS proposals was apparent; new actors could be identified, representing both human and nonhuman interests, but these might have to act in certain ways to protect the interests of the bank and as such would be classified as nonhuman, so it was important at this stage to enrol more key actors in the IS proposal, to establish a more stable network. 
The business case would need the approval of many actors (finance, risk management etc,) and be signed off by them to show that they had agreed on its scope and contents and that they could be held responsible if anything were to go wrong. We discovered a number of functions that actors used to exert agency in the business case network to which they belonged. These functions can be demonstrated by considering the nature of the human actors and technology being studied. In the prevailing state of IS investment, the executive committee was able to choose whether or not to invest in any kind of technology. Although the bank encouraged its staff to make proposals on how to solve business problems or to enhance the performance of the bank, uptake had been slow. Bank actors and their options for IS investment were evolving, as were their attitudes and behaviour related to IS investment. Although some study participants did not appear to recognise any form of evolutionary attitude, many important actors represented in the banking network did seem to have a major influence on evolutionary attitudes within the banking community. These actors were primarily managers, employers, IS investment, procedural arrangements, committees, documents, software and hardware.

Business case champions had to work hard to convince other actors to rally support from different perspectives and to align their interests to the champion's, especially in executive committee meetings. When documented, the business case became a nonhuman actor symbolising the interests, knowledge and vision of the business case champion. In order to enrol and mobilise more actors, the champion had to do three things: gain their support for the idea by communicating its status, show a vested personal interest in seeing the project succeed and oversee its management. According to CRBP12:

The business case champion is highly significant and in reality he has evolved further than what is specified in the position description. And I would like to make the point that even at this stage, it is obvious that the attention is on what kind of vision the business case document symbolises in terms of financial benefits to the business.

As was stated regarding the previous stage, whenever an IS proposal document needed to attract the attention of more (human) actors at CRBA, it would be further documented in new forms provided by the bank's procedures in order to be considered by the executive committee. To some extent, the way an IS project was inscribed would influence the design of the IS proposal; furthermore, it would have an impact on the approval process, as well as increasing the level of attention given to the project. To help accelerate the approval of an IS investment by the executive committee, it would be necessary to ensure that all the business problems, goals and needs had been formulated by means of inscription devices that would permit reliable and comparable arguments of business and IS actuality and evaluation across various projects before any further consideration. This would also help in performing IS evaluation, not just for the sake of technology but rather to achieve the bank's strategic goals. The business case champion would examine the network that was created by the efforts of various human actors in their constant pursuit of support for the business case when it was most needed. IS investment would be presented as very helpful in solving business problems, enhancing service quality, introducing new services and products or facing growing competition. 
CRBP19 considered justification to be particularly important:

I agree that IT investment has many fans in the bank, but on the other hand, it's obvious that no decision whatsoever can be taken without a precise justification, especially when it comes to IS investment. It's important to know what the effect of the decision would be on the bank if those decisions were made in light of those justifications when presented in a business case.

IS investment proposals were clearly supported by many actors in the bank, working together. These actors, when they pledged themselves to the idea of IS investment, could not act without being enrolled in a network with others who had the same interests. They would also need to be able to enrol more actors from other areas in order to turn the IS proposal which was formulated by their hard work into fact. In order for these other actors to be interested in enrolling in the network, they would need to be convinced by a justification of the proposal, so that it could be taken to the next level where decisions would be made to strengthen and stabilise the network before moving ahead to seek further endorsement. To gain support for it in the executive committee, its members would require more insight into the value of the proposal. As CRBP11 stated:

What makes the investment proposal is what the IS can do for the bank, in terms of what benefits would be seen with the implementation of the new system.

CRBP14 described the business case stage at CRBA as

...very formal. In this bank you need to go through very strict procedural arrangements which have to be followed in terms of the steps you need to go through.

By following these procedural steps, other human actors became fully involved in strengthening the business case network, improving the chances of obtaining the required approval of the executive committee to proceed with the project. In such complex networks a clearer picture needs to be created for the translation of the interests of actors to be become consistent with both business and IS realities. The process followed at CRBA to reach decisions concerning the business case for new IS consisted of a series of formal steps (nonhuman actors) that were enhanced through regulation and norms within the bank. However, in some situations this was not the case; ways could be found of gaining approval for the business case without going through each formal step in the process of IS evaluation, as CRBP5 stated:

There is no established way of defining the exact track to proceed with your proposal. What is evident is that there is a general direction that we should follow in order to get the proposal to where it should be going.

A significant factor which may have strengthened the network was that the bank had established procedures to apply agency in the actor network and to put pressure on other actors to become engaged. It had also established a good inscription standard which identified the bank's interest in this process. These procedures required that substantial steps be taken for the only goal of creating a business case prior to claiming the support of managers on the executive committee. CRBP7 outlined this process: 
A business case will be reviewed many times by all the people involved. The bank has an established track for granting approvals.

The detailed elements which had to be mentioned in the business case played a key part in it and would remind the actors what kind of information they had to focus on. This information must be fully detailed, to be able to inscribe the actors' interests without the risk of misunderstandings and to make it suitable for transfer to a new form using other main inscription elements. CRBP9 explained:

When there is a call for new IS, the business case must provide evidence of what problems they are trying to solve, the benefits of the new system and potential risks.

The business case should contain answers to questions such as what it was attempting to resolve or to explore, what were the possible risks of having this idea applied, what problems the actors were attempting to diagnose and how they could rally the endorsement of the senior members of the executive committee if they decided to take it to the next level. Before any decision was taken, enrolment into the IS investment actor network was accompanied by reinforcement of the business case, by strengthening the inscriptions within the network. Measurable IS proposals helped to focus committed actors on the purpose of the network and the interests of the business case, hence supporting a gradual shift towards black-box status.

According to CRBP2, champions were essential:

There are business case champions for all IS-related ideas. They play an essential part in structuring the business case to rationalize the necessitate for a given technology or application and define the potential advantages. Therefore they are required to contact various parties that may be significant in supporting the proposal in the committee.

The executive manager of any business area which initiated an IS idea was usually involved in sponsoring the proposal, as set out in the inscription rules of the bank, which required business people to sponsor any business project and to demonstrate the benefits they were claiming when recommending the idea. Thus, during meetings with the executive committee members, only the sponsor could approach them. CRBP11 explained this:

The importance of project sponsors can be seen during the many meetings where the business case is presented for further discussion. He is the only actor who can convince the committee, as he knows everything about the project.

The quality of relations among the actors involved in this procedure would have a great effect on the conversion of the business case (as focal object) in terms of what they could contribute to strengthen it. CRBP14 mentioned the importance of focusing on realistic proposals:

We don't have time in the bank to argue impractical thoughts which would distract us from other things that we need to give more attention to, otherwise we would waste a lot of time talking about ideas that had no chance of going any further.

As a nonhuman actor, this process can be seen as strengthening the execution of repeated and sustained assessment of the idea at any time, instead of assessing it at the finish of the project. 
Moreover, having the strategic interest of the actors inscribed in each business case is regarded to be another nonhuman actor which employed agency in the actor network to stop bad proposals from developing and to determine which proposal would go through and which not, prior to any further step was taken to explore it. The interest in this was for the executive committee to prevent unsupported proposals from progressing and to make it very difficult for those proposals which were not justified, or proven not to be beneficial, to progress and prosper. This justifies the initiation and emergence of actor networks around the IS proposal and indicates how each network became stable or was destabilized.

CRBP12 listed a number of major components of a business case:

A business case should include essential primary information to help decision makers assess the new IS and make them aware of all the relevant issues. This could be a description of an IS project, the financial and non-financial benefits, the revenues and potential risks of implementing such a system, which business people are involved and what department is going to accommodate the IS, what the main effects of the project are on the business with regard to market share, services, competition, customers, profits and cost, and the expected date to go live.

In this process, when dealing with a business case, it was necessary to identify a number of components in the proposal and explain every part of it before it could be taken further to attract the support of the executive committee (presented in figure 4-8). This process provided sufficient space for the actors to promote the IS project and strengthen it further. Actors in the network relied on these aspects of exploration in early transcripts of the IS proposal (included as component of the inscription form) to convert the IS proposal into a dissimilar key inscription document called the business case. Some of the information to be presented in the business case might be extremely important, while other material served to back up the idea. The following at least should be presented: description of the idea, its status as an element of organisational strategy or as a device developed to enhance performance, an estimate of whether revenue would increase, the size of the project and any risks associated with its implementation. These questions should be addressed: Is it a necessity or a matter of compliance with government regulations? Which stakeholders have been engaged? By whom has the project been sponsored? What department will contain and organize the IT? What are the expected monetary and non-monetary benefits? What are the main effects of the project on the business success determinates such as return on investment, market share, service levels, and competition? What is the approximate time to go live and initiate the system?

By adopting these patterns of inscription provided by the bank and incorporating them into the business case, the executives ensured that the business actors' interests and the assessment of the IS by the business and IS people had been inscribed. These patterns of documentary inscription were required to offer high quality descriptions of the prospective solutions, of how other systems would be affected and of any IT areas that might be impacted. They would also provide a clear indication of the cost and the resources aligned to achieve the development of IS by transforming the business case document so that it became sufficiently coherent and 
allowed the actors to visualize the shape of the IS project. In the case of the bank, according to CRBP5:

Different people from different disciplines are engaged in the discussion of the business case, from the finance, development, investment, operations and IT departments.

Coming from different disciplines - finance, risk management and IT among others-actors would bring their different expertise and background (nonhuman actors) to the discussion, examination and clarification of ideas, refining requirements to the next level of detail. Their vision would then be transformed, becoming more constructed and more relationally driven. thus the business and IS conceptions were interwoven and synchronized internally as the business case document incorporated all the actors that would be involved in this reality. However, CRBP3 explained that on some occasions some actors were ignored and not involved in the network, so their interests were not inscribed in the early shaping of the IS. This would have destabilised the IS investment evaluation network if they had stood up against the idea, but they did not.

CRBP8 said:

Various media are used to explain the business case and to convince decision makers, such as texts, diagrams, figures and numbers.

Thus, the business case would emerge as an inscription document using different media to explain what the actors wished to communicate through the iteration of entities such as texts, figures and numbers. This allowed the business case document to be a central point which would work to attract other actors to enrol in the network, starting a long process of deliberations to promote future business and IS opportunities. This would enable them to become intimately acquainted with the project, to take it further and to make a strong commitment to its performance. The shaping of an actor network around an IS project thus explains how the evaluation of a business case came about. The business case was not a significant object unless it produced an evaluation process. Rather, it was an inscription document that played a role in establishing relations among other related actors, who were engaged in a constructive discussion around the IS proposal in written form. They acted to integrate and merge several conflicting views of actuality into a more fractionally harmonious one, by enrolling actors and ensuring their involvement in presenting the benefits that would be attained through handling familiar troubles. Only when actors were involved in the elaborations for the business case could they see what advantages they may enjoy in terms of solving their problems and improving their work experiences. Such involvement generated interest in the project embedded in the business case because they could see the expected outcome. Actors were involved in constructive debate around an IS investment project in scripted form by the launch of an IS investment proposal, which was an inscription artefact providing the momentum to act in a way that would construct and strengthen relations among relevant actors, as was stated by CRBP2:

We gather in a meeting and speak over all the unsettled matters. The entire meeting will be authenticated. In these meetings we need to get them to one joint sense concerning this 
business case, although they have a vision which eventually makes them see things from different angles. This is a process to get them to accept to share the similar views about the same IS project.

A problem reported to arise in joint action meetings was that of individual differences among the executive committee members. When the actors behaved in a way which made the diverse visions of the main actors more coherent, the ensuing debates and talks opened the way for obstacles to rise. The actors' diverse visions and ideas would be presented in different forms of documents, based on the capability of each actor to conceive and understand the underlying business case. Some actors would remain silent during the meeting and others would talk continually. Some would highlight unfavorable points that should be included in the inscription documents, referring to possible risks, while others would insist on the benefits of approving the business case. While this was happening, some people who had never been engaged in such discussions would prefer to immerse themselves silently in the documents, data provided and sketches in the business case, in an attempt to understand the project. CRBP4 raised this point:

Stakeholders have different attitudes to expressing their views. I have noticed different kinds of behaviour during our meetings... Of course it is difficult, but no more nor less than in any other meeting. The usual amount of noise goes on, and if you were a member of the committee, you'd want that. You'd want vigorous debate going on about this.

If an actor is unable to conceive the vision behind a project, this may result in a failure to enrol him into the actor network. In the case of the bank, it was inscribed in company policy that certain crucial actors were obligatorily enrolled in the network, so any such failure could destabilise and weaken the network, since their support was considered crucial to the passage of a particular proposal. Prior to the finish of a meeting, while some declared their conviction and corroboration for the project, some would be listing possible problems and focusing their comments on insufficiency that might present, whereas others would declare that it was not yet possible to make a definitive decision and that more time was needed to study and revise the business case documents. Because of this difference of opinions between actors, decisions would be settled only after numerous meetings held at executive committee level with the participation of both business people and IS specialists. Together with proposals for different solutions, the results on which the outcome would be decided would be presented and the executive committee would act accordingly. CRBP6 elaborated:

Not every business case gets approval for the project to go ahead. Deficiencies in the project might occur at a number of levels from the committee members. Hence at each level you would need to prove the relative importance of the business case. Not every business case gets to be approved by the bank, nor gets rejected.

It was not easy to obtain approval for a business case, especially when it was as important and crucial as that for an IS investment project; therefore, not all proposals put forward to decision makers were approved. They had to be considered with other proposals for prioritisation to decide their relative significance, so as to decrease the number of proposals. Gaining executive committee approval would enhance and further stabilize the actor network, 
providing decisive impetus towards engaging other actors in the stages ahead, but there was no certainty that momentum would be sustained, nor that the business case would ultimately be approved at the next stage.

\section{Discussion}

\subsection{Request for Proposals (Business Case)}

The degree of rigidity in the process of IS evaluation and the dependence on a specific method tends to vary among banks, depending on a combination of many factors, namely organisational structure, culture and strategy. According to CRBA executives, they were led by the IS proposal through the evaluation process and this represented the key to informing their assessment, which was used in making the final decision. IS evaluation started when the bank decided to invest in a new IS. The idea was then embodied in an IS proposal, a document which was often developed at various stages to make recommendations in support of funding the proposed IS. The IS proposal can be seen to represent the vision and arguments symbolising the IS in the document and the value of the contribution made by the idea to the business domain, as well as its technological and financial consequences. The contribution to the business field focused on the long-range benefits, via improvements in the organisation's products or services, while the technological contribution was evaluated by criteria such as conformance with technology standards, market acceptance of the technologies used and continuity of supply. Each IS proposal had a great influence because the idea that it embodied attracted other stakeholders and aligned them with that vision.

In interview, the CIO referred to the importance of informally suggesting an idea for IS investment and then approaching other key stakeholders throughout the bank to gain their support, long before the formal process started. As the idea was then marketed to gain support, the IS proposal would attract relevant stakeholders with a shared interest in the idea. This would always have the effect of making the predilection of the different stakeholders explicit and arguable. Making an investment decision would then take into account key figures such as those in senior management, IT management and project management. The IS proposal would operate on behalf of the interests of enrolled stakeholders, tending to focus the debate and discussions on major issues such as the orientation of the investment and its benefits, so that the proposal would be aligned with these. The investment orientation was divided into infrastructure, business needs and market influence, while the benefits were categorized as enhancing productivity, minimising risk and expanding the business. These categories were seen to overlap to some extent.

\subsection{Formality and Informality in IS Pre-Evaluation}

The evaluation process followed by CRBA, as revealed by the case study, were similar to those described in the extant literature. One of the findings of this research is related to the effects of process style on decision makers. Interviewees stated that the bank used formal IS evaluation; on the other hand, there was evidence of informal IS evaluation apparently taking place. The explanation for this is that the two styles of IS evaluation were applied at different times and for different reasons. Many examples of IS investment proposals in practice were described throughout the study by various interviewees, who stated that they were managed 
in a way that avoided the need to follow the officially designated evaluation process (formal). Executives did not go through any formal evaluation when the investment was considered to have a high value. when senior executives were persuaded that an IS investment was worthy, work was frequently started outside the process. Here anew, there was no formal authority to continue, but a reliance on so-called executive intuition. This contradicts the findings of Martins and Kambil (1999), who provide evidence of managers' susceptibility to prior experience with IT when making new investment decisions. Managers with a positive experience of existing IT tended to be biased favourably towards new IT investments. This bias was also observed in managers whose organisations engaged reactively in IT investment - possibly explained by the fewer failures they had experienced after cautious investment. Bonabeau (2003) argues that intuition (informal evaluation) can be misleading, especially in complex projects.

Decision making at CRBA often relied on the intuition (informal evaluation) and experience of executives, particularly in complex cases, even though formal IS evaluation appeared to be preferable, since no one was willing to take risks regarding major expenditure. The study results suggest that the informal use of intuition was accommodated within the formal process of IS evaluation. Again, to institutionalise and systemise IS investment decisions which executives had already taken prior to the evaluation process, these decisions had to be formally supported by IS proposals that had passed through the evaluation process. This shows how some of the members of the executive committee to which investment proposals were submitted were the same people who had taken the decisions previously. The IS proposal was not the product of objectively following the process, nor was it socially constructed, but rather it emerged from the relations among the actors forming around it. This is in line with the findings of (Serafeimidis and Smithson 2003) that informal channels were applied to get agreements with senior authorization committees and generally resulted in the success of the proposals. Because of the essence of assessment, informal actions and influences were anticipated. Evaluators behaved politically to 'support' the results of business sponsors so as to persuade the senior executives of their viability.

Formal IS evaluation at CRBA did not follow a fixed sequence of steps that offered a firm structure for the evaluation process. It provided formal justification techniques so that decision makers could evaluate projects against established criteria. Furthermore, when the structure of the process was more tightly defined, the consequence was greater confidence in the result of the IS evaluation. Formal IS evaluation also provided confidence in decisions, which had positive impacts on IS decision outcomes. On the other hand, informal IS evaluation took place for many reasons, especially when the process of IS evaluation was too complex and the interests of the stakeholders played an essential role in IS evaluation. Informal evaluation occurred when the system to be implemented had proven to be beneficial somewhere else.

\section{Conclusion}

Evaluation in practice is mainly concerned with the question of how the relational substantiality of different actors in the network components, develops and revolves around the IS proposal. The relations of interest here were those that appeared to have taken place between different actors as a result of the efforts of the focal actor to inscribe their interests in 
the IS proposal and to enrol them in the network. As a result, various actors were enrolled in the actor network of the IS proposal manuscript. Their relations will have influenced the IS proposal manuscript as it developed, became richer and offered a tighter argument in favour of the proposed investment. The manuscript developed through various stages and was enhanced throughout the process of evaluating the proposal, as a result of the relationships formed within the actor network.

Actors contributed through their active communication with each other across all the stages of IS development to articulate the IS proposal manuscript, by inscribing their visions and interests. Thus, the development of the IS proposal manuscript through different evaluation stages was able to overcome many challenges and barriers arising from the application of the system, by refining the proposal again and again, as these barriers might arise again at any time. The IS proposal as an inscription tool was not ultimately fixed and stable, since ideas, beliefs and attitudes might change. The proposal was viewed as a relational entity facilitating collaboration, but not in the sense of bringing all the actors together to resolve their differences; rather, each would try to impose his opinion on the others in pursuit of what he saw as the best interests of the bank from his own department's point of view. Confrontation between actors via such relations is indeed an indication that change was being disputed and ultimately evident; otherwise, an IS proposal would represent a symbolic entity with no potential influence. The IS proposal manuscript can thus be seen as an enacted communication device presenting evidence of disputable interests and visions, seeking to change the current incrementally inherited systems.

It can be concluded that the evaluation process continued to develop throughout the process, under the influence of various actors that were invited to enrol in the network. As a consequence of their involvement in inscribing their visions and interests, they would find weaknesses in the proposal and exploit them, while building on its strengths. Each actor would act differently, resulting in an unpredictable emergent process which would result in the final modified form of the manuscript. Thus, the inscription process would be significantly altered by the influence of the different actors. To sum up, the case study shows that the expertise and experience of the enrolled actors contributed to the maturity of the IS proposal and that they were the key elements in the evaluation process. We learn from the study that evaluation was not denied through the process of developing the IS proposal, but rather that this was essential to the implementation of the evaluation as the IS proposal was being formed and not - as the literature suggests is common practice - after being submitted for final confirmation. Thus, before the selection of the IS, it may be preferable to conduct evaluation during proposal development. The evaluation was also found to take a multiple perspective, not a purely financial one. This holistic approach to IS evaluation was taken because decision makers had to ensure that the IS proposal embodied no potential risk and that the proposed systems were fully aligned with the organisation's priorities and strategies, among other criteria. It is evident from the study that a rigorous evaluation methodology cannot choose a system on the basis of financial criteria alone.

Myers (1997) argues that the richest insights to be gained from IS interpretive studies are in the domain of the human, social and organisational aspects of IS development in context. 
Thus, the experiences explored in the present case study had the potential to offer rich insights (Myers, 1994a; Walsham, 1995b) into the development of IS proposals. To cast light on this formerly obscure area, I implemented ANT to reveal its inherent complexity and the heterogeneity of its elements in its socio-technical context. By opening the black box of IS proposal development, this study thus offers rich, new and valuable insights into the ways in which IS proposals develop. These insights concern the close relationship between the IS pre-evaluation process and the organisational context through IS proposal development. Hitherto, there has been limited empirical research into IS pre-evaluation as practised in developing countries (Al-Yaseen et al., 2007), so part of the contribution to knowledge of the present study is that the fieldwork was conducted in a developing country, Jordan where there is a dearth in such research (Al-Zu'bi et al, 2015; Abdallah, 2013; Al-Zu'bi et al., 2010; Al-Zu'bi \& Tsinopoulos, 2012).

The study also draws specific implications and contributes knowledge of IS pre-evaluation in banking to a broader audience beyond academia. First, it offers rich insights into how IS proposals come into being and are made to work (or not) in general and in the context of Jordan in particular, by examining the experiences of those dealing with the development of IS proposals in a leading Jordanian bank. From the perspective of interpretive case study, these experiences have general methodological implications for IS evaluation beyond the particular bank studied. This is not to say that the case study is representative of all banks in Jordan or worldwide. However, existing and potential IS evaluation can draw from the experiences of this case, particularly as it relates to the banking environment of Jordan.

It is possible to propose a policy for Jordanian Banking Sector which acknowledges the complexity of decision making process in terms of its many stakeholders involved in shaping the decision network. The policy would suggest that IS proposal would need the approval of many stakeholders and to be signed off by them to show that they had agreed on its scope and contents in terms of its linkage to the future financial plan and that they could be held responsible if anything were to go wrong. Thus the bank in following this policy will encourage only the presentation of serious IS project proposal to the investment decision makers.

\section{Limitations of the Study}

One important limitation of the research that it was uniquely concerned with pre-evaluation, addressing only the development of the IS proposal and thus limiting the scope of the study to one part of the IS lifecycle. This restriction, enforced by the fact that the case study organisation did not carry out ex-post evaluation, precluded the consideration of a number of issues, such as the accountability of the decision makers for the IS investment result, the dynamics of the ongoing evaluation and the supervision of IS projects. Another limitation is that the case study represents a snapshot in time of IS evaluation practices. One or more longitudinal studies would have added to the understanding of the evaluation process by further examining attempts at both ex-ante and ex-post evaluation. 


\section{Recommendations for Future Work}

This study explored only pre-evaluation, while future research should be extended to evaluation throughout the IS lifecycle. Moreover, it would be of value in testing the theory to extend it to small and medium-sized enterprises, to determine the effect-if any-of organisational size differences. One new direction of research would be to investigate barriers to the development of IS proposals. This could be a direct extension of the work described in this paper, studying one or more cases in the Jordanian banking sector.

\section{References}

Abdallah, A.B. (2013).The Influence ofSoft andHard Total Quality Management (TQM) Practices on Total Productive Maintenance (TPM) in Jordanian Manufacturing Companies. International Journal of Business and Management, 8(21), 1-13. http://dx.doi.org/10.5539/ijbm.v8n21p1

Al-Shehab, A. J., R. T. Hughes, \& G. Winstanley (2005).Modelling risks in IS/IT projects through causal and cognitive mapping. The electronic journal of information systems evaluation, 8(1), 1-10.

Al-Yaseen, H., A. Al-Gweri, \& S. Al-Jaghoub (2007). IS/IT Investment Appraisal, Prior and Post Implementation Evaluation in Jordanian Firms. IADIS International Conference Applied Computing.

Ali, B. M., \& B. Younes (2012).The Process of Decision Making and the Evaluation of Investment Projects in Information Technology. Journal of Administrative Sciences and Technology 2012, 1.

Alshawi, S., Z. Irani, \& L. Baldwin (2003).Benchmarking information technology investment and benefits extraction. Benchmarking, An International Journal, 10(4), 414-423. http://dx.doi.org/10.1108/14635770310485015

Al-Zu'bi, Z.M.F., Alshurideh, M., Abuhamed, A., \& Ghannajeh, A.M. (2015b). A Qualitative Analysis of Product Innovation in Jordan's Pharmaceutical Sector. European Science Journal, 11(4), 474-503.

Al-Zu'bi, Z. M. F. (2010). Collaboration in Mass Customisation, Exploring the impacts of suppliers and lead users (1st ed.). VDM Verlag, Germany.

Al-Zu'bi, Z. M. F., \& Tsinopoulos, C. (2012a).Suppliers versus Lead Users, Examining Their Relative Impact on Product Variety. Journal of Product Innovation Management, 29(4), 667-680. http://dx.doi.org/10.1111/j.1540-5885.2012.00932.x

Al-Zu'bi, Z. M. F., \& Tsinopoulos, C. (2012b).An Outsourcing Model for Lead Users, An Empirical Investigation. Production Planning and Control, 24(4/5), 1-10.

Anandarajan, A., \& H. J. Wen (1999).Evaluation of information technology investment. Management decision, 37(4), 329-339. http://dx.doi.org/10.1108/00251749910269375 
Ashrafi, R., \& J. Mueller (2014).Delineating IT Resources and Capabilities to Obtain a Competitive Advantage and Improve Performance for a Firm. Information Systems Management, null-null.

Avison, D., J. Horton, P. Powell, \& J. Nandhakumar (1995). Incorporating evaluation in the information systems development process. Proceedings of the 3rd Evaluation of Information Technology Conference Henley, UK.

Bacon, C. (1992). The Use of Decision Criteria in Selecting Information Systems/Technology Investments. MIS Quarterly 16(3), 335-353. http://dx.doi.org/10.2307/249532

Ballantine, J., M. Levy, A. Martin, I. Munro, \& P. Powell (2000).An ethical perspective on information systems evaluation. International Journal of Agile Management Systems, 2(3), 233-241. http://dx.doi.org/10.1108/14654650010356149

Ballantine, J., \& S. Stray (1998).Financial appraisal and the IS/IT investment decision making process. Journal of Information Technology (Routledge, Ltd.), 13(1), 3-14. http://dx.doi.org/10.1080/026839698344927

Ballantine, J. A., R. D. Galliers, \& S. J. Stray (1996).Information systems/technology evaluation practices, evidence from UK organizations. Journal of Information Technology 11(2), 129 - 141. http://dx.doi.org/10.1080/026839696345342

Ballantine, J. A., \& S. Stray (1999).Information systems and other capital investments, evaluation practices compared. Logistics Information Management, 12(1/2), 78-93. http://dx.doi.org/10.1108/09576059910256286

Bannister, Frank, Berghout, Egon, Griffiths, P., \& Remenyi and Dan (2004). Tracing the Eclectic (or maybe even Chaotic) Nature of ICT Evaluation. 11th European Conference on Information Technology Evaluation (ECITE). Royal Netherlands Academy of Arts and Sciences, Amsterdam11-12 November., 41-51.

Bannister, F., \& D. Remenyi (1999).Value perception in IT investment decisions. Electronic Journal of Information Systems Evaluation, 2(2).

Bannister, F., \& D. Remenyi (2000).Acts of faith, instinct, value and IT investment decisions. Journal of Information Technology (Routledge, Ltd.), 15(3), 231-241. http://dx.doi.org/10.1080/02683960050153183

Bannister, F., \& D. Remenyi (2000).Acts of faith, instinct, value and IT investment decisions. Journal of information Technology, 231-241. http://dx.doi.org/10.1080/02683960050153183

Barrett, M., \& G. Walsham (2004). Making Contributions From Interpretive Case Studies, Examining Processes of Construction and Use. Information Systems Research. B. Kaplan, D. Truex, III, D. Wastell, A. T. Wood-Harper and J. DeGross, Springer US. 143, 293-312. 
Barua, A., C. H. Kriebel, \& T. Mukhopadhyay (1995).Information technologies and business value, An analytic and empirical investigation. Information Systems Research, 6(1), 3. http://dx.doi.org/10.1287/isre.6.1.3

Betz, C. T. (2006). Architecture and Patterns for it Service Mana gement, Resource Planning, and Governance, Making Shoes for the Cobbler's Children, San Francisco, CA, Morgan Kaufmann.

Black, I. (2006). The presentation of interpretivist research. Qualitative Market Research, An International Journal, 9, 319-324. http://dx.doi.org/10.1108/13522750610689069

Black, I. (2006). The presentation of interpretivist research. Qualitative Market Research, An International Journal, 9(4), 319-324. http://dx.doi.org/10.1108/13522750610689069

Bonabeau, E. (2003).Don't trust your gut. Harvard Business Review, 81(5), 116.

Bowen, P. L., M. Y. D. Cheung, \& F. H. Rohde (2007).Enhancing IT governance practices, A model and case study of an organization's efforts. International Journal of Accounting Information Systems, 8(3), 191-221. http://dx.doi.org/10.1016/j.accinf.2007.07.002

Brynjolfsson, E., \& L. M. Hitt (2000).Beyond Computation, Information Technology, Organizational Transformation and Business Performance. Journal of Economic Perspectives, 14(4), 23-48. http://dx.doi.org/10.1257/jep.14.4.23

Burke, L. A., \& M. K. Miller (1999).Taking the mystery out of intuitive decision making. The Academy of Management Executive (1993-2005), 91-99.

Callon, M. (1991). Techno-economic networks and irreversibility. In, A Sociology of Monsters Essays on Power,Technology and Domination. London, Rutledge.

Caridi, M., A. Moretto, A. Perego, \& A. Tumino (2014).The benefits of supply chain visibility, A value assessment model. International Journal of Production Economics, 151, 1-19. http://dx.doi.org/10.1016/j.ijpe.2013.12.025

Chan, Y. E., \& B. H. Reich (2007).IT alignment, what have we learned? Journal of Information Technology, 22(4), 297-315. http://dx.doi.org/10.1057/palgrave.jit.2000109

Chung, E., \& C. McLarney (1999). When giants collide, strategic analysis and application. Management Decision, 37(3), 233-248. http://dx.doi.org/10.1108/00251749910264479

Clemons, E. K. (1991).Evaluation of strategic investments in information technology. Communications of the ACM, 34(1), 36. http://dx.doi.org/10.1145/99977.99985

Connolly, D. J. (2008). Investing in information technology to grow firm value.

Coombs, C. R. (2015). When planned IS/IT project benefits are not realized, a study of inhibitors and facilitators to benefits realization. International Journal of Project Management, 33(2), 363-379. http://dx.doi.org/10.1016/j.ijproman.2014.06.012

Currie, W. (1995). Management strategy for IT, An international perspective, UK, Pitman Publication. 
Dietz, R., \& T. Renkema (1995). Planning and justifying investments in information technology, A framework with case study illustrations. Proceedings of the Second European Conference on Information Technology Investment Evaluation. A. Brown and D. Renkema. Birmingham, UK, The Operational Research Society, 28-41.

Dos Santos, B. L. (1991).Justifying investments in new information technologies. Journal of Management Information Systems, 7(4), 71-90.

Ezingeard, J., Z. Irani , \& P. Race (1998).Assessing the value and cost implications of manufacturing information and data systems, an empirical study. European Journal of Information Systems, 7(4), 252-260. http://dx.doi.org/10.1057/palgrave.ejis.3000309

Farbey, B., F. Land and D. Targett (1992).Evaluating investments in IT. Journal of Information Technology (Routledge, Ltd.), 7(2), 109.

Farbey, B., F. Land, \& D. Targett (1993). How to assess your IT investment, A study of methods and practice, Butterworth-Heinemann.

Farbey, B., F. Land, \& D. Targett (1999).Moving IS evaluation forward, learning themes and research issues. The Journal of Strategic Information Systems, 8(2), 189-207. http://dx.doi.org/10.1016/S0963-8687(99)00021-9

Farbey, B., F. L., \& and D. Targett (1999b). Evaluating investments in IT, Finnding a framework. In Beyond IT Productivity Paradox L. Willcocks and S. Lester, (eds) Wiley, Chichester, $183 \pm 216$.

Goldkuhl, G., \& J. Lagsten (2012). Different roles of evaluation in information systems research. Workshop on IT Artefact Design and Workpractice Intervention, 10 June 2012, Barcelona.

Gunasekaran, A., P. E. D. Love, F. Rahimi, \& R. Miele (2001). A model for investment justification in information technology projects. International Journal of Information Management, 21(5), 349-364. http://dx.doi.org/10.1016/S0268-4012(01)00024-X

Gunasekaran, A., E. W. Ngai, \& R. E. McGaughey (2006). Information technology and systems justification: A review for research and applications. European Journal of Operational Research, 173(3), 957-983. http://dx.doi.org/10.1016/j.ejor.2005.06.002

Häkkinen, L., \& O. P. Hilmola (2008). ERP evaluation during the shakedown phase: lessons from an after-sales division. Information systems journal, 18(1), 73-100. http://dx.doi.org/10.1111/j.1365-2575.2007.00261.x

Hallikainen, P., \& L. Chen (2012). A holistic framework on information systems evaluation with a case analysis. Leading Issues in ICT Evaluation, 1(43).

Hallikainen, P., J. Heikkilä, K. Peffers, T. Saarinen, \& F. Wijnhoven (1998). Evaluating information technology projects in Finland: procedures, follow-through, decision-making and perceived evaluation quality. Journal of Global Information Management (JGIM), 6(4), 23-33. http://dx.doi.org/10.4018/jgim.1998100103 
Harvey, L., \& M. Myers (1995). Scholarship and practice: The contribution of ethnographic research methods to bridging the gap. Information Technology \& People, 8(3), 13-27. http://dx.doi.org/10.1108/09593849510098244

Hirschheim, R., \& S. Smithson (1999). Evaluation of information systems: a critical assessment. Beyond the IT productivity paradox. L. P. Willcocks and S. Lester. West Sussex, UK, Wiley series in information systems. John Wiley \& Sons Ltd: 381-410.

Holland, D., \& G. Skarke (2008). Business \& IT alignment: Then \& now, a striking improvement. Strategic Finance-Montvale, 89(10), 42.

Irani, M., \& P. Anandan (1998). A unified approach to moving object detection in 2D and 3D scenes. Pattern Analysis and Machine Intelligence, IEEE Transactions on 20(6), 577-589. http://dx.doi.org/10.1109/34.683770

Irani, Z. (2002). Information systems evaluation: navigating through the problem domain. Information \& Management, 40(1), 11-24. http://dx.doi.org/10.1016/S0378-7206(01)00128-8

Irani, Z., \& A. Ghoneim (2002). Identifying, Managing, and Controlling Information System Costs: An Exploratory Case Study. AMCIS 2002 Proceedings, 170.

Irani, Z., A. Ghoneim, \& P. E. D. Love (2006). Evaluating cost taxonomies for information systems management. European Journal of Operational Research, 173(3), 1103-1122. http://dx.doi.org/10.1016/j.ejor.2005.07.007

Irani, Z., \& P. Love (2008). Evaluating information systems: public and private sector, Elsevier/Butterworth-Heinemann.

Irani, Z., \& P. E. D. Love (2001). Information systems evaluation: past, present and future. European Journal of Information Systems, 10(4), 183-188. http://dx.doi.org/10.1057/palgrave.ejis.3000408

Irani, Z., \& P. E. D. Love (2002). Developing a frame of reference for exante IT/IS investment evaluation. European Journal of Information Systems, 11(1), 74-82. http://dx.doi.org/10.1057/palgrave.ejis.3000411

Jamieson, K., P. Hyland, \& C. Soosay (2007). An exploration of a proposed balanced decision model for the selection of Enterprise Resource Planning Systems. International Journal of Integrated Supply Management, 3(4), 345-363. http://dx.doi.org/10.1504/IJISM.2007.013368

Katz, A. I. (1993). Measuring technology's business value. Information Systems Management, 10(1), 33-39. http://dx.doi.org/10.1080/10580539308906910

Kennedy, A., \& R. Mills (1992). Post-completion auditing: A source of strategic direction?. Management Accounting, 70(5), 26-28.

Keyes-Pearce, S. (2005). IT Value Management in Leading Firms: The Fit Between Theory and Practice. PhD thesis, 2005, Australia, The University of Sydney. 
Kim, Y. J., \& G. L. Sanders (2002). Strategic actions in information technology investment based on real option theory. Decision Support Systems, 33(1), 1-11. http://dx.doi.org/10.1016/S0167-9236(01)00134-8

Klein, H. and M. Myers (1999). A set of principles for conducting and evaluating interpretive field studies in information systems. MIS Quarterly, 23(1), 67-93. http://dx.doi.org/10.2307/249410

Kumar, K. (1990). Post implementation evaluation of computer-based information systems: current practices. Communications of the ACM, 33(2), 203-212. http://dx.doi.org/10.1145/75577.75585

Latour, B. (1987). Science in action: how to follow scientists and engineers through society, Harvard University Press, Cambridge, MA.

Latour, B. (1992). Where are the missing masses? The sociology of a few mundane artifacts In Bijker WE, Law J (eds.) Shaping Technology/Building Society: Studies in Sociotechnical Change. Cambridge, MA, MIT Press: 225-258.

Latour, B. (2000). Pandora's Hope, Essays on the Reality of Science Studies, Harvard University Press, London

Law, C. C. H., \& E. W. T. Ngai (2005). IT business value research: a critical review and research agenda. International Journal of Enterprise Information Systems 1(3), 35-55. http://dx.doi.org/10.4018/jeis.2005070103

Leem, C. S., \& I. Kim (2004). An integrated evaluation system based on the continuous improvement model of IS performance. Industrial Management \& Data Systems, 104(2), 115-128. http://dx.doi.org/10.1108/02635570410522080

Lin, C., \& G. Pervan (2000). Realising the benefits of IS/IT investments in Australian organisations. Eleventh Australasian Conference on Information Systems (ACIS 2000), Brisbane, Australia, December 6-8.

Lin, C., \& G. Pervan (2003). The practice of IS/IT benefits management in large Australian organizations. Information \& Management, $41(1), \quad 13-24$. http://dx.doi.org/10.1016/S0378-7206(03)00002-8

Lopez, A. K., \& G. D. Willis (2004). Descriptive versus Interpretive phenomenology: Their contribution to nursing knowledge. Qualitative Health Research, 14(5), 726-735. http://dx.doi.org/10.1177/1049732304263638

Lovallo, D., \& D. Kahneman (2003). Delusions of success. How optimism undermines executives' decisions. Harvard Business Review, 81(7), 56.

Love, P. E. D., \& Z. Irani (2004). An exploratory study of information technology evaluation and benefits management practices of SMEs in the construction industry. Information \& Management, 42(1), 227-242. http://dx.doi.org/10.1016/j.im.2003.12.011 
Love, P. E. D., Z. Irani, \& D. J. Edwards (2005). Researching the investment of information technology in construction: An examination of evaluation practices. Automation in Construction, 14(4), 569-582. http://dx.doi.org/10.1016/j.autcon.2004.12.005

Lubbe, S., \& D. Remenyi (1999). Management of information technology evaluation-the development of a managerial thesis. Logistics Information Management, 12(1/2), 145-156.

Maizlish, B., \& r. Handle (2005). IT portfolio management step by step: unlocking the business value of technology. Hoboken, NJ, John Wiley and Sons.

Marsh, L., \& R. Flanagan (2000). Measuring the costs and benefits of information technology in construction. Engineering Construction and Architectural Management, 7(4), 423-435. http://dx.doi.org/10.1046/j.1365-232x.2000.00177.x

Marshall, P., \& J. McKay (2002). Evaluating the benefits of electronic commerce in small and medium enterprises. Australian Journal of Information Systems, 9(2), 135-147. http://dx.doi.org/10.3127/ajis.v9i2.200

Martins, L. L., \& A. Kambil (1999). Looking back and thinking ahead: Effects of prior success on managers' interpretations of new information technologies. The Academy of Management Journal ,42(6), 652-661. http://dx.doi.org/10.2307/256986

McAulay, L., N. Doherty, \& N. Keval (2002). The stakeholder dimension in information systems evaluation. Journal of Information Technology, 17(4), 241-255. http://dx.doi.org/10.1080/0268396022000017734

Mitev, N. N., \& A. E. March (1998). Small businesses and information technology: risk, planning and change. Journal of Small Business and Enterprise Development, 5(3), 228-245. http://dx.doi.org/10.1108/EUM0000000006784

Myers, M. (1994a). Dialectical hermeneutics: A theoretical framework for the implementation of information systems. Information Systems Journal, 5, 51-70. http://dx.doi.org/10.1111/j.1365-2575.1995.tb00089.x

Myers, M. D. (1997). Interpretive research in information systems. Information systems: An emerging discipline. J. Mingers and F. Stowell. London, The McGraw Hill Companies: 239-266.

Nijland, M. (2004). IT cost benefit management improvement from a critical perspective. The Electronic Journal of Information Systems Evaluation, 7, 1-11.

Nutt, P. (1997). Better Decision-Making: a Field Study. Business Strategy Review, 8(4), 45-52. http://dx.doi.org/10.1111/1467-8616.00047

Oates, B. J. (2005). Researching information systems and computing. London, Sage.

Oates, B. J. (2006). Researching information system and computing, sage publications, London, UK. 
Paul, R. J. (2007). Challenges to information systems: time to change. European Journal of Information Systems, 16(3), 193-195. http://dx.doi.org/10.1057/palgrave.ejis.3000681

Pennington, D., \& F. Wheeler (1998). The Role of Governance in IT Projects: Integrating the Management of IT Benefits. in Proceedings of the Fifth European Conference on IT Investment Evaluation.

Powell, P. (1992). Information Technology Evaluation: Is It Different? The Journal of the Operational Research Society, 43(1), 29-42. http://dx.doi.org/10.1057/jors.1992.4

Powell, P. L. (1999). Evaluation of information technology investments: Business as usual? Beyond the IT Productivity Paradox L. Willcocks and S. Lester West Sussex, UK John Wiley and Sons Ltd: $151-182$

Primrose, P., \& R. Leonard (1987). Performing investment appraisals for advanced manufacturing technology. Cost Management, 2, 34-42.

Remenyi, D., \& M. Sherwood-Smith (1999). Maximize information systems value by continuous participative evaluation. Logistics Information Management, 12, 14-25. http://dx.doi.org/10.1108/09576059910256222

Ross, J. W., \& P. Weill (2002). Six IT Decisions Your IT People Shouldn't Make. Harvard Business Review, 80(11), 84-92.

Schryen, G. (2013). Revisiting IS business value research: what we already know, what we still need to know, and how we can get there. European Journal of Information Systems, 22(2), 139-169. http://dx.doi.org/10.1057/ejis.2012.45

Seddon, P. B., V. Graeser, \& L. P. Willcocks (2002). Measuring organizational IS effectiveness: an overview and update of senior management perspectives. ACM SIGMIS Database, 33(2), 11-28. http://dx.doi.org/10.1145/513264.513270

Semich, J. W. (1994). Here's how to quantify IT investment benefits. Datamation 40(1), 45-48.

Serafeimidis, V., \& S. Smithson (2003). Information systems evaluation as an organizational institution - experience from a case study. Information Systems Journal, 13(3), 251-274. http://dx.doi.org/10.1046/j.1365-2575.2003.00142.x

Sims, J., P. Powell, \& R. Vidgen (2015). Investment appraisal and evaluation: preserving tacit knowledge and competitive advantage. International Journal of Business and Systems Research, 9(1), 86-103. http://dx.doi.org/10.1504/IJBSR.2015.066822

Small, M. H., \& I. J. Chen (1995). Investment justification of advanced manufacturing technology: an empirical analysis. Journal of Engineering and Technology Management, 12(1-2), 27-55. http://dx.doi.org/10.1016/0923-4748(95)00003-5

Sohal, A. S., \& L. Ng (2001). The role and impact of information technology in Australian business. Journal of Information Technology, 13(3), 201-217. http://dx.doi.org/10.1080/026839698344846 
Standing, C. (1998). Myths and the art of deception in information systems. Work Study, 47(1), 5-13. http://dx.doi.org/10.1108/00438029810196667

Straw, B. (1990). Rationality and justification in organizational life. Information and cognition in organizations. L. L. Cummings and B. M. Straw. London, JAI Press Inc: 53-88.

Symons, V., \& G. Walsham (1991). The evaluation of information systems: a critique. The Economics of Information Systems and Software. R. Veryard. Oxford, Butterworth-Heinemann Ltd. http://dx.doi.org/10.1016/b978-0-7506-1122-0.50011-7

Tallon, P. (2008). Inside the adaptive enterprise: an information technology capabilities perspective on business process agility. Information Technology and Management, 9(1), 21-36. http://dx.doi.org/10.1007/s10799-007-0024-8

Tatnall, A., \& A. Gilding (1999). Actor-network theory and information systems research, Citeseer.

Thomaidis, N. S., N. Nikitakos, \& G. D. Dounias (2006). The Evaluation of Information Technology Projects: A Fuzzy Multicriteria Decision Making Approach. International Journal of Information Technology \& Decision Making, 5(1), 89-122. http://dx.doi.org/10.1142/S0219622006001897

Walsham, G. (1993). Interpreting Information Systems in Organizations. New York, John Wiley.

Walsham, G. (1995b). The emergence of Interpretivism in IS research. Information Systems Research, 6(6), 376-394. http://dx.doi.org/10.1287/isre.6.4.376

Walsham, G. (1997). In Information systems and qualitative research. L. (Eds, A. S., Liebenau, J. and DeGross, J. I.). London, Chapman and Hall: pp. 466-480.

Walsham, G. (2006). Doing interpretive research. European Journal of Information Systems, 15, 320-330. http://dx.doi.org/10.1057/palgrave.ejis.3000589

Ward, J. (1990). A portfolio approach to evaluating information systems investments and setting priorities. Journal of Information Technology, 5(4), 222-231. http://dx.doi.org/10.1057/jit.1990.46

Ward, J., \& E. Daniel (2006). Benefits management: Delivering value from IS \& IT investments, John Wiley \& Sons Chichester.

Weber, Y., \& N. Pliskin (1996). The effects of information systems integration and organizational culture on a firm's effectiveness. Information \& Management, 30(2), 81-90. http://dx.doi.org/10.1016/0378-7206(95)00046-1

Weill, P. (1990). Do computers pay off. International Center for Information Technologies, Washington, DC, USA. 


\section{Macrothink}

Journal of Management Research

ISSN 1941-899X 2016, Vol. 8, No. 1

Willcocks, L. (1992). Evaluating information technology investments: research findings and reappraisal. Information Systems Journal, 243-268. http://dx.doi.org/10.1111/j.1365-2575.1992.tb00081.x

Willcocks, L. (1992). It evaluation: Managing the catch 22. European Management Journal, 10(2), 220-229. http://dx.doi.org/10.1016/0263-2373(92)90072-C

Willcocks, L. P., \& S. Lester (1997). In search of information technology productivity: assessment issues. Journal of the Operational Research Society, 48(11), 1082-1094. http://dx.doi.org/10.1057/palgrave.jors.2600463

Willcocks, L. P., \& S. Lester (1999b). In search of Information Technology productivity: assessment issues. In Beyond the IT productivity paradox,(ed. L.P. Willcocks and S. Lester). Wiley, Chichester: 69-97.

Wilson, M., \& D. Howcroft (2005). Power, politics and persuasion in IS evaluation: a focus on relevant social groups. The Journal of Strategic Information Systems, 14(1), 17-43. http://dx.doi.org/10.1016/j.jsis.2004.11.007

Wolfe, R. A. (2007). Organizational Innovation: Review, Critique and Suggested Research Directions. Journal of Management Studies, 31(3), 405-431. http://dx.doi.org/10.1111/j.1467-6486.1994.tb00624.x 